\title{
Crise do Progresso, Antifascismo e Ciências Sociais: a Journée d'histoire et de psychologie du travail et des techniques' (Toulouse, junho de 1941)
}

Isabelle Gouarné2

\section{Resumo}

Em junho de 1941, uma Jornada de Psicologia e História do Trabalho e das Técnicas foi organizada em Toulouse com a participação de importantes representantes das ciências sociais francesas do entreguerras (Marc Bloch, Lucien Febvre, Marcel Mauss, Georges Friedmann, Ignace Meyerson, entre outros). Esse encontro se constituiu como um dos raros momentos de reflexão coletiva realizado pelas ciências sociais republicanas sob o regime de Vichy, quando elas se tornaram alvo de violentas acusações. Esse colóquio de 194I representa, assim, um esforço de reafirmação do papel social e político das ciências sociais universitárias herdeiras da tradição durkheimiana: em um contexto de forte politização e à medida que era preciso defender esse projeto, ele se tornou manifesto pelo modo de organização das ciências e dos saberes que implica, pelo olhar que dirige sobre a crise social e política bem como pelas afinidades que mantém com a ideologia do progresso.

Palavras-chave: Ciências sociais. Crise política. Engajamento. Segunda Guerra Mundial.

Construídas na França sobre a base do ideal republicano, as ciências sociais universitárias tiveram que enfrentar ataques e denúncias repetidas desde a sua institucionalização. Com as reformas de ensino que promoveram

Tradução de Allana Meirelles (USP). Revisão da tradução de Miguel Palmeira e Marcia Consolim. Agradeço a Isabelle Gouarné pelos esclarecimentos às dúvidas em relação ao texto original.

2 Chargé de recherche no Centre National de la Recherche Scientifique (CNRS), membro do CURAPP-ESS.

E-mail: isabelle_gouarne@hotmail.com. 
os novos saberes, no início do século XX, as ciências sociais suscitaram críticas violentas. Apoiada pela aliança dos homens de letras com a Igreja, a reação anticientífica visava particularmente à tradição durkheimiana (GEIGER, 1979; SERRY, 2004; SAPIRO, 2004), que exercia uma influência profunda no conjunto das ciências humanas (MUCCHIELLI, 1998; HEILBRON, 2015) ${ }^{3}$ e cuja ambição era elaborar uma resposta racional às questôes políticas e sociais do momento. Embora essa aspiração pudesse estar encarnada nos projetos de reformas, em uma conjuntura favorável graças ao apoio de elites políticas republicanas, nem por isso deixou de ser permanentemente contestada ${ }^{4}$. As redefiniçóes sucessivas do sistema intelectual e conceitual das ciências sociais francesas herdeiras de Durkheim podem, assim, ser analisadas como tentativas de deslocar e reformular essa ambição política inicial, em razão das rivalidades internas do campo intelectual e da evolução da conjuntura ideológica e política.

Ao retomar, depois de Francine Muel-Dreyfus (2004), o período de Vichy, pretende-se investigar a relação das ciências sociais francesas com as questôes políticas. Com efeito, deter-se sobre essa situação crítica, nos limites de uma "sócio história de curta duração" (GOBILLE, 2008), permite compreender o momento em que se intensificou "o trabalho de significação" e de "definiçãao da situaçáo", em resposta à "ruptura da inteligibilidade" - aberta, na França, pela derrota de 1940 para a Alemanha nazista - e à incerteza quanto ao curso dos acontecimentos. Assim, as lógicas políticas subjacentes ao trabalho das ciências sociais, que operam "em tempos ordinários, de forma mais invisível e lenta”, tornam-se manifestas. Da mesma forma, notam-se as redefiniçóes intelectuais que se operam nesse momento crítico, em que o ethos profissional é violentamente desafiado pelas medidas de exclusão e de censura bem como pela reorientação das ciências sociais sob Vichy no âmbito da Revolução Nacional. As acusações às ciências sociais puderam, então, se expressar sem restriçóes, pois encontraram um potente apoio político no Estado francês (MUEL-DREYFUS, 2004). Desde o verão de 1940, o regime de Vichy condenava o intelectualismo como uma das causas da derrota e se esforçava em remediar o fato por meio

3 Para o entreguerras, ver: Heilbron (2015).

4 Ver o recente enfoque de Lahire, 2016. 
da difusão do espírito da Revolução Nacional no seio das universidades. Nas ciências sociais, em particular, as leis de exclusão administrativa que atingiram, em 1940-1941, os franco-maçons, os comunistas e a esquerda em geral e, sobretudo, os judeus levaram à expulsão de muitos professores e pesquisadores, entre os quais se pode citar os mais renomados e promissores, na época: Marcel Mauss, Raymond Aron, Georges Friedmann, Georges Gurvitch, Henri Lévy-Bruhl, Claude Lévi-Strauss, Paul Rivet, em sociologia e etnologia; Marc Bloch ${ }^{5}$, Paul Léon, Paul Mantoux, em história; Émile Benveniste, Jules Bloch e Marcel Cohen, em linguística; J.-M. Lahy, Ignace Meyerson, Henri Wallon, em psicologia. (SINGER, 1992) ${ }^{6}$. Essas interdições profissionais bem como as dificuldades materiais e a dispersão geográfica logo tornaram difícil toda a vida científica coletiva. Os principais centros de pesquisa que haviam federado as ciências sociais no entreguerras abrandaram ou cessaram suas atividades. Por outro lado, novos espaços de pesquisa foram criados, visando promover uma ciência social ancorada na biologia e a serviço da ordem moral (DROUARD, 1992) ${ }^{7}$ - a exemplo da Fondation Alexis Carrel, criada em 1941.

Desde então, raros foram os momentos coletivos nas ciências sociais republicanas. Um deles foi a Journée d'Histoire et de Psychologie du Travail et des Techniques que o psicólogo Ignace Meyerson organizou, em 23 de junho de 1941, em Toulouse - cidade-refúgio onde se encontravam, sob zona livre, muitos intelectuais depois da desmobilização ou do êxodo desde 1940. ${ }^{8}$ Participaram desse colóquio, ao lado dos universitários de Toulouse (entre os quais o geógrafo Daniel Faucher e o helenista André Aymard), alguns intelectuais que, apoiando-se na herança durkheimiana, contribuíram fortemente para o desenvolvimento das ciências sociais do entreguerras. Em primeiro lugar, Marcel Mauss, sobrinho e herdeiro intelectual de Émile Durkheim: residente de zona ocupada, não pôde, porém, participar da Jornada, a não ser de forma indireta, enviando o texto de sua

5 Marc Bloch se beneficiou, entretanto, de isenções concedidas aos judeus por "serviços excepcionais" prestados ao Estado francês e foi, assim, reintegrado ao ensino superior em julho de 194I. Ele faz parte dos raros universitários judeus mantidos em função por Vichy.

6 Ver igualmente: Rouquet (2010).

7 Ver igualmente: F. Muel-Dreyfus (1996) e Rosental (2003).

8 Sobre a situação das ciências sociais em Toulouse durante a Segunda Guerra Mundial, ver: Chandivert (2016). 
comunicação. Outro convidado de destaque foi o historiador Marc Bloch, que partiu de Clermont-Ferrand para o que chamou de uma "viagem de

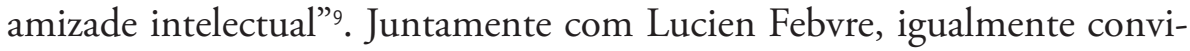
dado para esse colóquio em Toulouse ${ }^{10}$, Bloch havia formado o polo mais inovador das ciências sociais dos anos 1930: a revista Annales d'Histoire Économique et Sociale que eles lançaram, em 1929, foi projetada a partir do modelo de L’Année Sociologique e tinha como ambição renovar o conjunto das ciências sociais ao assumir muitas das exigências intelectuais durkheimianas. Assim, a revista conseguiu atrair jovens historiadores, sociólogos e etnólogos, entre os quais Fernand Braudel, Ernest Labrousse, Jacques Soustelle, André Varagnac e Georges Friedmann (que também participou, em junho de 1941, do colóquio em Toulouse organizado por Meyerson).

Esse colóquio, cujos trabalhos foram publicados em 1948 no Journal de Psychologie Normale et Pathologique, constitui um dos raros vestígios das reflexóes coletivas que as ciências sociais republicanas produziram, sob Vichy, com o objetivo de reafirmar seu papel social e político, interpretar os acontecimentos e definir seu sentido. Trata-se do projeto das ciências sociais que, à medida que era contestado, e era preciso defendê-lo, torna-se manifesto particularmente em três aspectos: o modo de organizaçáo das ciências e dos saberes que ele implica, o olhar que dirige sobre a crise social e política bem como as afinidades que mantém com a ideologia do progresso.

\section{Defesa de uma configuração de saberes}

A iniciativa dessa Jornada de estudos de junho de 1941 sobre "o trabalho e as técnicas" veio de Ignace Meyerson" (1888-1983), psicólogo hoje conhecido pelo programa marxista em "psicologia histórica" que ele desenvolverá, após a Segunda Guerra Mundial, com seu aluno e amigo Jean-Pierre Vernant, quando os dois se tornaram membros do Partido Comunista francês. Seu percurso intelectual foi, de fato, marcado por engajamentos políticos intensos.

\footnotetext{
9 Segundo a expressão utilizada por Ignace Meyerson em seu prefácio na edição dos trabalhos da Jornada (MEYERSON, 1948).

10 Como Marcel Mauss, Lucien Febure não pode viajar para Toulouse, mas enviou o texto de sua comunicação.

II Ver essa nota em: Boulland, Pennetier (2012) e López (2008).
} 
De origem judaica e polonesa, Meyerson se exilou na Alemanha e, em seguida, na França, em 1906, depois de ter participado do movimento insurrecional russo-polonês de 1905, em Varsóvia, como socialista-revolucionário. Acolhido em Paris por seu tio, o filósofo das ciências Émile Meyerson, ele pôde seguir cursos de ciências (licence ${ }^{12}$ em 1913), de letras (licence em 1918) e de medicina, alcançando reconhecimento no universo da psicologia científica francesa: recrutado, em 1921, como préparateur ${ }^{13}$ no Laboratoire de Psychologie Expérimentale dirigido por Henri Piéron ${ }^{14}$ na École Pratique des Hautes Études (seção 3), tornou-se diretor-adjunto, em 1923, uma vez obtida a nacionalidade francesa.

Em outubro de 1940, Ignace Meyerson foi transferido da École Pratique para a Universidade de Toulouse, onde se instalou depois da derrota; em dezembro do mesmo ano, foi exonerado de seu posto pela aplicação das leis raciais de Vichy. Sua reação foi, então, dupla: política e científica. Ao final de 1941, depois de engajamentos socialistas e antifascistas, ingressou na Resistência ao lado de Jean-Pierre Vernant: sob o pseudônimo de Julien Montfort, ele participou da organização da Armée Secrète, do Corps Francs de la Libération e das Forces Françaises de l'Intérieur de la Haute Garonne. Em relação ao plano científico, Meyerson fundou a Sociedade de Estudos Psicológicos de Toulouse, em maio de 1941, a partir do modelo das sociedades científicas que, como a Sociedade de Filosofia e a Sociedade de Estudos Clássicos, funcionava na Faculté des Lettres de Toulouse como seminários de pesquisa ${ }^{15}$. Essa Sociedade de Estudos Psicológicos tornou-se, segundo os termos de Jean-Pierre Vernant, um "centro de vida intelectual livre em uma zona não ocupada". De fato, esse foi um lugar de reunião anti-Vichy onde os intelectuais exonerados de seus postos em razão das leis raciais de Vichy - e engajados desde 1940-1941 nas redes da Resistência

12 "Licence" corresponde ao segundo grau universitário, conferido por um diploma nacional de ensino superior obtido ao final de três anos de estudos depois do baccalauréat (N.T.).

13 Normalmente vinculado a uma disciplina ou laboratório, o préparateur é encarregado da preparação de atividades práticas mais elementares (N.T.).

14 Colaborador da Université de Toulouse no laboratório de Villejuif, desde os anos 1900, H. Piéron (1881-1964) teve um papel importante, na França, na institucionalização e na profissionalização da psicologia científica, que ele ancorou nas ciências biológicas. Ver: Carroy, Ohayon e Plas (2006).

15 Estatutos depositados em 12 de maio de 1941 por J.-P. Vernant na Prefeitura (dossiê da associação da Sociedade de Estudos Psicológicos, Archives Départementales de la Haute-Garonne). 
nascente - desempenharam claramente um papel ativo: por exemplo, o filósofo Vladimir Jankélévitch ${ }^{16}$, o escritor e crítico literário Benjamin Crémieux (RACINE, 2011) ou ainda o sociólogo Georges Friedmann ${ }^{17}$.

\section{A ciência republicana mobilizada contra Vichy}

Foi justamente para o lançamento dessa sociedade científica que Ignace Meyerson organizou, em poucas semanas, a jornada de estudos consagrada à psicologia e à história do trabalho e das técnicas. Contudo, a realização desse colóquio em junho de 1941 náo era absolutamente evidente. Os obstáculos políticos eram numerosos num momento em que circulavam as notícias das primeiras detençôes de intelectuais. Muitas ausências nessa Jornada poderiam ser explicadas pelas perseguiçóes políticas que atingiram os círculos intelectuais em 1940-1941 - por exemplo, as de Henri Wallon e de J.-M. Lahy, ambos especialistas em psicologia do trabalho.

Ignace Meyerson conseguiu, contudo, reunir nessa Jornada de estudos os representantes eminentes da ciência republicana do entreguerras, graças aos laços de sociabilidade que construiu, desde sua chegada à França, nos meios intelectuais republicanos e, desde 1940, em Toulouse - na Universidade, mas também no Instituto Católico, "meca da resistência intelectual" (CABANEL, 1994).

Tabela I - Lista dos Participantes da Journée d'Études d'Histoire et de Psychologie du Travail et des Techniques (junho de 194I)

\begin{tabular}{lccc}
\hline $\begin{array}{l}\text { Sobrenome/Prenome } \\
\text { Data: } \text { nasc.-morte }\end{array}$ & Meio social de origem & Disciplina & $\begin{array}{c}\text { Último posto ocupado } \\
\text { (anos 1 930) }\end{array}$ \\
\hline $\begin{array}{l}\text { Aymard, André } \\
\text { 1900-1964 }\end{array}$ & $\begin{array}{c}\text { Família de professores } \\
\text { primários }\end{array}$ & História & $\begin{array}{c}\text { Professor, Université } \\
\text { Toulouse }\end{array}$ \\
\hline $\begin{array}{l}\text { Bloch, Marc } \\
\text { 1886-1944 }\end{array}$ & $\begin{array}{c}\text { Família alsaciana, de origem } \\
\text { judaica. Pai universitário }\end{array}$ & História & $\begin{array}{c}\text { Professor, Université de } \\
\text { Paris }\end{array}$ \\
\hline $\begin{array}{l}\text { Camichel, Charles } \\
\text { 1871-1966 }\end{array}$ & $\begin{array}{c}\text { Pai pastor da lgreja } \\
\text { reformada }\end{array}$ & Física & $\begin{array}{c}\text { Professor, Université } \\
\text { Toulouse }\end{array}$ \\
\hline
\end{tabular}

16 Ver a notícia biográfica (por F. Schwab) em: Boulland e Pennetier (2012) e Jankélévitch (2015).

17 Ver o testemunho de Friedmann (2004). Na mesma obra, ver também: Almaric (2004). 


\begin{tabular}{|c|c|c|c|}
\hline $\begin{array}{l}\text { Sobrenome/Prenome } \\
\text { Data: nasc.-morte }\end{array}$ & Meio social de origem & Disciplina & $\begin{array}{c}\text { Último posto ocupado } \\
\text { (anos 1930) }\end{array}$ \\
\hline $\begin{array}{l}\text { Delaruelle, Étienne } \\
\text { 1904-1971 }\end{array}$ & Pai universitário & História & $\begin{array}{l}\text { Professor no grande } \\
\text { seminário, Toulouse }\end{array}$ \\
\hline $\begin{array}{l}\text { Faucher, Daniel } \\
\text { 1882-1970 }\end{array}$ & $\begin{array}{c}\text { Meio popular de artesãos. } \\
\text { Esposa professora primária, } \\
\text { de religião protestante }\end{array}$ & Geografia & $\begin{array}{c}\text { Professor, Université } \\
\text { Toulouse }\end{array}$ \\
\hline $\begin{array}{l}\text { Febvre, Lucien } \\
1878-1956\end{array}$ & Pai professor associado & História & $\begin{array}{c}\text { Professor, Collège de } \\
\text { France }\end{array}$ \\
\hline $\begin{array}{l}\text { Friedmann, Georges } \\
\text { 1902-1977 }\end{array}$ & $\begin{array}{c}\text { Pai banqueiro. Família de } \\
\text { origem judaica }\end{array}$ & Sociologia & Professor na escola Boulle \\
\hline $\begin{array}{l}\text { Hadamard, Jacques } \\
\text { 1865-1963 }\end{array}$ & $\begin{array}{l}\text { Pai professor do liceu. } \\
\text { Família de origem judaica }\end{array}$ & Matemática & $\begin{array}{c}\text { Professor, Collège de } \\
\text { France }\end{array}$ \\
\hline $\begin{array}{l}\text { Lalande, André } \\
\text { 1867-1963 }\end{array}$ & $\begin{array}{l}\text { Pai professor, tornou-se } \\
\text { inspetor da Academia } \\
\text { Esposa de religião } \\
\text { protestante. }\end{array}$ & Filosofia & Professor, Université Paris \\
\hline $\begin{array}{l}\text { Mauss, Mauss } \\
1872-1950\end{array}$ & $\begin{array}{c}\text { Pai negociante. Sobrinho } \\
\text { de Émile Durkheim. Família } \\
\text { de origem judaica }\end{array}$ & Etnologia & $\begin{array}{c}\text { Professor, Collège de } \\
\text { France }\end{array}$ \\
\hline $\begin{array}{l}\text { Meyerson, Ignace } \\
\text { 1888-1983 }\end{array}$ & $\begin{array}{l}\text { Nascido na Polônia. Pai } \\
\text { médico. Sobrinho do } \\
\text { filósofo Émile Meyerson. } \\
\text { Família de origem judaica }\end{array}$ & Psicologia & Diretor de estudos ${ }^{18}$, EPHE \\
\hline $\begin{array}{l}\text { Vignaux, Paul } \\
\text { 1904-1987 }\end{array}$ & $\begin{array}{l}\text { Pai funcionário das } \\
\text { contribuições diretas }\end{array}$ & $\begin{array}{l}\text { Filosofia, } \\
\text { História das } \\
\text { religiões }\end{array}$ & Diretor de estudos, EPHE \\
\hline
\end{tabular}

Os doze participantes dessa Jornada foram recrutados entre as frações mais politizadas do campo universitário-científico ${ }^{19}$. A maior parte deles pertencia à geração dreyfusard, nascida nos anos de 1860-1880 (Marc Bloch, Charles Camichel, Daniel Faucher, Lucien Febvre, Jacques Hadamard, André Lalande, Marcel Mauss, Ignace Meyerson). Em ruptura

18 "Directeur d'études" é a expressão usada para se referir aos professores-pesquisadores vinculados a instituições de pesquisa e responsáveis por organizar seminários (N.T.).

19 Este estudo biográfico se inspira na análise desenvolvida por Charle (1990, 1994). 
com o legitimismo ${ }^{20}$ universitário do início da Terceira República, eles adotaram uma orientação política à esquerda (socializante), especialmente depois do caso Dreyfus, que havia revelado seu descontentamento com a República oficial. Nos anos 1930, muitos deles recomeçaram a se engajar fortemente no contexto da luta antifascista - em particular, no Comité de Vigilance des Intellectuels Antifascistes - e por meio desse engajamento se associaram a uma nova geração intelectual, representada na Jornada de junho de 1941 por Georges Friedmann e Paul Vignaux. Estes, preocupados também em refundar as relaçóes dos intelectuais com a República e com o movimento dos trabalhadores, engajaram-se ativamente, desde os anos 1920, em organizaçóes políticas de esquerda - ligadas ao movimento comunista, por Friedman, e ao movimento democrata-cristão, por Vignaux.

Apesar das diferentes trajetórias militantes, das divergências políticas que poderiam opô-los, além das diferenças geracionais, todos esses intelectuais compartilhavam uma mesma adesão aos valores republicanos, enraizados em suas histórias familiares individuais. A mobilidade social ascendente que alguns haviam conhecido os inclinava a aderir ao ideal meritocrático republicano: ainda que as reformas republicanas com vistas à abertura do recrutamento social da Universidade tenham sido um "fracasso parcial” (CHARLE, 1990, 1994, p. 71), André Aymard e Daniel Faucher, por exemplo, ambos de origem popular, delas se beneficiaram. Os outros eram originários de famílias intelectuais, cuja ética do desinteresse e da excelência universitária se combinava fielmente a uma tradição política republicana (por exemplo, Marc Bloch, Lucien Febvre, Jacques Hadamard e André Lalande). Essa adesão aos valores republicanos também era fruto do pertencimento às minorias religiosas: protestante (Charles Camichel, Daniel Faucher e André Lalande, cujas esposas eram de religiāo protestante) e, sobretudo, judaica (Marc Bloch, Georges Friedmann, Jacques Hadamard, Marcel Mauss e Ignace Meyerson). O engajamento republicano foi, assim, "[...] o prolongamento de seu combate secular pela igualdade de tratamento religioso.” (CHARLE, 1990, 1994, p. 197).

Tais afinidades políticas se refletiam no campo universitário-científico, os intelectuais republicanos frequentemente situando-se nos polos mais

20 Partidários da linhagem mais antiga dos Bourbons destronada pela linhagem de Orleans na Revolução de julho de 1830. Opositores dos Orleans e de Napoleão III (LAROUSSE, 20I8b) (N.T.). 
inovadores. Muitos deles se formaram na École Normale Supérieure (ENS), que constituía o lugar de socialização privilegiado dos professores de esquerda. Eles ensinavam geralmente nas instituiçóes da Nouvelle Université, as mais próximas do ideal inspirado na ciência alemã, como a EPHE, o Collège de France ou ainda a Université de Strasbourg, e haviam participado das inovaçôes intelectuais das últimas décadas, tanto nas ciências ditas duras (por exemplo, Jacques Hadamard, em matemática) como nas ciências sociais. Nessa Jornada de estudos, reencontraram-se os intelectuais que contribuíram para o avanço da escola durkheimiana e da filosofia republicana, desde a primeira geração (Marcel Mauss ou ainda André Lalande) até o entreguerras. A maior parte deles era sensível às renovaçóes propostas pela revista Annales de March Bloch e Lucien Febvre, estando diretamente associados a elas desde os anos 1930 (Georges Friedmann) ou se esforçando para introduzi-las em seu próprio domínio de pesquisa (André Aymard nos estudos sobre a Grécia antiga; Étienne Delaruelle e Paul Vignaux na história das religiōes).

\section{Continuar o esforço}

Embora em clima de grande inquietude, a mobilização intelectual impulsionada por Ignace Meyerson obteve sucesso porque atendeu a uma necessidade, qual seja a de "manter intactos os espaços intelectuais e humanos” (BLOCH, 1941), como escreveu Marc Bloch em uma carta a Ignace Meyerson. Com essa Jornada de estudos, a intenção era, em primeiro lugar, reconstituir "a configuração dos saberes" (FABIANI, 2005) que havia sustentado as ciências sociais republicanas e, assim, manifestar coletivamente a recusa às medidas de Vichy.

Tal preocupação se refletiu no programa da Jornada de estudos de junho de 1941, pelo qual Meyerson se esforçou em recriar, a exemplo do que existiu nos anos 1930, as condiçóes para um diálogo entre disciplinas que envolveu a psicologia, a história (Lucien Febvre, Marc Bloch, André Aymard), a história da filosofia (o medievalista Paul Vignaux), a história religiosa (o padre Étienne Delaruelle), a sociologia e a etnologia (Marcel Mauss e Georges Friedmann), e a geografia (Daniel Faucher). Essa configuração de saberes estava, além disso, aberta à filosofia e às ciências da natureza: participaram dos trabalhos dessa Jornada o matemático Jacques Hadamard, o físico da Université de Toulouse Charles Camichel, e André Lalande, que no entreguerras havia promovido uma filosofia racionalista 
aberta à sociologia durkheimiana, em particular no grande dicionário que ele dirigiu, Vocabulaire Technique et Critique de la Philosophie (Vocabulário Técnico e Crítico da Filosofia). André Lalande, morando em Albi, não pôde comparecer à reunião em Toulouse por razôes de saúde, enviando, porém, sua contribuição, assim como Lucien Febvre e Marcel Mauss.

Ignace Meyerson havia exposto essa ambição interdisciplinar na reuniâo fundadora da Sociedade de Estudos Psicológicos, em 15 de maio de 1941, na Faculté des Lettres de Toulouse, na "sessão de estudo de método geral”. Ele apresenta, como introdução, o percurso intelectual que ele pretendia desenvolver nesse âmbito, qual seja uma psicologia científica e objetiva, de modo a estudar "o espírito" a partir de manifestaçóes concretas (obras, instituições): em primeiro lugar, em suas "funçóes sintéticas e complexas"; em segundo lugar, no que diz respeito aos "fundamentos da vida mental"; finalmente, nos "princípios diretores do pensamento como a identidade e a causalidade". Sua proposta era associar a psicologia às outras disciplinas das ciências sociais a fim de aperfeiçoar a compreensão do "homem total" (MEYERSON, 1948). Depois dessa apresentação, uma série de comunicaçóes proferidas pelos universitários de Toulouse especificavam as possíveis relaçóes que a psicologia poderia manter com a antropologia, a geografia, a filologia e a linguística, a história, os estudos literários, o direito e a economia bem como os estudos religiosos ${ }^{21}$.

A interdisciplinaridade defendida por Ignace Meyerson era antes de tudo uma forma de reafirmar os vínculos da psicologia com as ciências sociais. Considerando a sociologia como "uma psicologia especial", consagrada ao "estudo das representaçôes coletivas" (MEYERSON, 1939 apud LÓPEZ, 2008, p. 52), Ignace Meyerson pretendia construir, na linha dos trabalhos de Marcel Mauss e de Henri Hubert e no espírito do diálogo entre as disciplinas, "uma história social das categorias do espírito humano" 22 . O que ele reivindicava era, portanto, uma psicologia articulada às ciências sociais durkheimianas.

21 I. Meyerson considerou publicar os trabalhos desse encontro, mas o projeto não pôde ser realizado. Entretanto, é possivel encontrar um resumo dessas intervenções na ata da sessão redigida para o Bulletin de l'Université et de l'Académie de Toulouse, de outubro-novembro de 1941.

22 Segundo afirma M. Mauss (1990, p. 33 I-362, 333). 
Essa postura estava, entretanto, longe de ser compartilhada pelo conjunto dos psicólogos. No entreguerras, o lugar dessa disciplina nas ciências era objeto de debate no seio da psicologia científica - formada, contudo, a partir de um grupo homogêneo de cientistas republicanos e de dreyfusards. Progressivamente, surgia uma clivagem entre os que que, de um lado, como Henri Piéron, defendiam uma psicologia enraizada nas ciências naturais e, de outro lado, como Ignace Meyerson, Charles Blondel, J.-M. Lahy ou ainda Henri Wallon, que pretendiam orientar a psicologia às ciências sociais. Essa divisão intelectual, além disso, não era neutra politicamente. Desde os anos 1930, ela se referia, em parte, a diferentes papéis políticos: de um lado, à figura do "cientista-especialista" a serviço do Estado, encarnada por Henri Piéron e, de outro lado, à figura do psicólogo engajado nas lutas políticas em favor de um projeto de transformação social. É sintomático o fato de que Henri Piéron manteve-se sempre distante dos partidos políticos ${ }^{23}$, enquanto J.-M. Lahy, I. Meyerson e H. Wallon foram simpatizantes ou membros do Partido Comunista francês ${ }^{24}$. Todos os três foram também vítimas da repressão de Vichy: Meyerson foi exonerado de seu posto, como foi mencionado, logo depois da promulgação das leis antissemitas; H. Wallon e J.-M. Lahy o foram por razóes políticas ${ }^{25}$. Assim, desde 1940-1941, a tendência sociologizante e historicizante da psicologia científica foi marginalizada. A psicofisiologia, por sua vez, floresceu sob Vichy (HENRY, 2012): ela encontrou seu lugar na Fondation Française pour l'Étude des Problèmes Humains de Alexis Carrel, cuja visão era reagrupar o conjunto das ciências sob a direção da medicina a fim de servir ao higienismo social promovido pela Revolução Nacional (MUEL-DREYFUS, 1996).

A essa visão de ciência se opunha a Sociedade Toulousiana de Estudos Psicológicos, criada por Ignace Meyerson, ao reafirmar outra concepção de interdisciplinaridade. Tratava-se assim de perseguir o projeto unitário das

23 Ver a autobiografia de H. Piéron, em: Parot e Richelle (1992).

24 Ver a nota de H. Wallon (por N. Racine) e a de J.-M. Lahy (por M. Trebitsch e J. Girault) em: Boulland e Pennetier (2012). Ver igualmente Gouarne (2007)_e Turbiaux (1982-1983; 2006).

25 Companheiros de trajetória, J.-M. Lahy (1872-1943) e H. Wallon (1879-1962) se engajaram ativamente nas organizações ligadas ao Partido Comunista ou sustentadas pela União Soviética nos anos 1930. Ambos desenvolveram uma reflexão original sobre a psicologia e o marxismo. $\mathrm{H}$. Wallon, que testemunhou em favor dos deputados comunistas em seus processos de março de 1940, foi demitido de seu posto de professor no Collège de France de 1941 a 1944. Da mesma forma. J.-M. Lahy, que teve, além do seu engajamento filosoviético, um papel de primeiro plano no Grande Oriente da França, foi removido de seu posto na EPHE, em 194I, por pertencer à maçonaria. 
ciências sociais durkheimianas, pensado frequentemente, desde os anos 1930, sob a forma de uma "psicologia coletiva" (MUCCHIELLI, 1994; MARCEL, 2004), sustentado por uma comunidade intelectual reagrupada, apesar dos esforços de clivagem disciplinar da época: por historiadores (Henri Berr, Marc Bloch, Lucien Febvre); psicólogos (Charles Blondel, Ignace Meyerson, Henri Wallon) e os sociólogos ou etnólogos durkheimianos (Maurice Halbwachs, Lucien Lévy-Bruhl, Marcel Mauss). Do ponto de vista institucional, ele se desenvolveu no âmbito do Centre International de Synthèse, da revista dos Annales ou do Journal de Psychologie Normale et Pathologique, mas também nos projetos interdisciplinares pontuais (como a Encyclopédie Française, o Vocabulaire Historique etc.) (BIARD; BOUREL; BRIAN, 1997). A orientação intelectual da Sociedade de Estudos Psicológicos tinha então um forte sentido político, no momento em que o regime de Vichy lançava uma ofensiva contra as ciências sociais durkheimianas e se esforçava em promover uma ciência social enraizada na biologia, a serviço da ordem moral.

\section{Crise política e Ciências Sociais}

Ao reconstituir, tanto quanto possível, as condições de trabalho e de diálogo das ciências sociais, os participantes da Jornada pretendiam reafirmar o seu direito de intervenção política diante de outros tipos de intelectuais (do campo universitário e, mais amplamente, dos campos intelectual e político, como escritores, polemistas e outros "especialistas") e de seus discursos sobre a sociedade, seus males e remédios. O tema escolhido para a Jornada de estudos de junho de 1941, "o trabalho e as técnicas", não tinha nada de inofensivo. Essa escolha significava o prisma através do qual a crise social e política deveria ser analisada pelas ciências sociais. Com efeito, "o trabalho e as técnicas" havia sido uma temática de pesquisa fortemente estudada nas ciências sociais francesas, desde o fim do século XIX, em particular nos círculos intelectuais republicanos dreyfusards, preocupados em combater a escalada do discurso antimoderno que denunciava os males da Razão, da Ciência e da Máquina, com o objetivo de renovar a aliança estabelecida nos anos de 1870 com as elites políticas sobre a base da filosofia positivista ${ }^{26}$.

26 Sobre a evolução das relações entre as elites universitárias e as elites republicanas, ver: Charle (1990, 1994). Sobre a articulação entre a filosofia de Auguste Comte e o projeto republicano, ver igualmente: Fabiani (20I0). 


\section{O trabalho e as técnicas: demanda social e problemática intelectual}

A partir dos anos 1890, como demonstrou Christophe Charle, o credo republicano que havia sido compartilhado pela elite universitária foi perdendo força: "ao legitimismo dominante nos meios universitários vis-à-vis o regime (no início da Terceira República), segue-se uma reivindicação crescente de autonomia e, até mesmo, nas geraçóes mais novas, de uma posição crítica de vanguarda”. Uma fração das novas elites universitárias que buscava remediar as falhas da República opta então pelo socialismo e pretende, assim, conciliar seus engajamentos com investimentos intelectuais racionalistas nas "ciências do contemporâneo", concebidas como "fundamentos da ação política" (CHARLE, 1990, p. 82, p. 91). Foi nesse meio universitário engajado em favor do movimento operário que o tema "o trabalho e as técnicas" suscita um novo interesse entre historiadores (por exemplo, Paul Mantoux e Georges Renard), sociólogos (François Simiand e A. Espinas) e psicólogos (PROCHASSON, 1993).

As ciências sociais republicanas foram assim mobilizadas a partir de uma reflexão sobre o trabalho e as técnicas em uma conjuntura ideológica marcada por um clima antimoderno (RASMUSSEN, 1996). De fato, o otimismo quanto à técnica, dominante no século XIX, suscitou inúmeras críticas nas primeiras décadas do século XX, em particular entre os homens das letras. Essa contestação do progresso se inscrevia nas lutas que opunham, desde o fim do século XVIII, o campo universitário-científico e o campo literário. A aliança da Ciência e da República havia constituído uma ameaça às pretensóes dos homens de letras ao universal que, cada vez mais, eram rivalizados pelos universitários e cientistas que valorizavam a competência e a "utilidade social" de seus saberes (SAPIRO, 2004). Em contrapartida, a mobilização dos escritores se apoiava na difusão das correntes pessimistas e antimodernas, defendendo a ideia de "decadência" e a "degenerescência” contra a ideia modernidade política, técnica e cientí$\mathrm{fica}^{27}$. Ela deu origem ao que Marc Bloch nomeará como "a literatura de renúncia” no depoimento que redigirá em 1940 com o título L'Étrange défaite (A Estranha Derrota):

27 Sobre essa reação antimoderna, ver principalmente: Jarrige (2004) e Raimond (2000). 
Ouço o rádio pregando diariamente o "retorno à terra”. [...] Essas ideias bucólicas não são, no entanto, coisas de hoje. Bem antes da guerra, toda uma literatura da renúncia já havia nos familiarizado com elas. Estigmatizava o "americanismo". Denunciava os perigos da máquina e do progresso. Louvava, por contraste, a pacífica doçura de nossos campos, a gentileza de nossa civilização de pequenas cidades, a amabilidade e, ao mesmo tempo, a força secreta de uma sociedade convidada a permanecer cada vez mais resolutamente fiel aos modos de vida do passado. (BLOCH, 1990, p. 180-181).

Assim, nos anos 1920-1930, a defesa, cara a Charles Maurras, da "Civilização" e do Ocidente contra o materialismo, o racionalismo, o bolchevismo ou ainda o maquinismo industrial dava forma a uma visão do mundo social suscetível de reunir, em torno da Action Française, amplas fraçóes do mundo literário (SAPIRO, 1999). O eco político que essa retórica antimoderna reencontrou nos anos 1930, com a crise econômica de 1929 e a escalada do fascismo, levou novamente os meios universitário-científicos, ao menos suas fraçóes mais politizadas, a reagir. Nas ciências sociais, essa questão encontrou assim atualidade novamente (VATIN, 2012):

O problema das técnicas, de seu papel na vida das sociedades e, especialmente, da máquina e do maquinismo, encontra-se colocado cruamente diante das pessoas por uma crise econômica sem precedentes. A partir da demanda do público, os historiadores colocam-no em termos de história. (FEBVRE, 1938b).

Essa temática se tornou um objeto de pesquisa privilegiado na equipe dos Annales, ligados aos jovens intelectuais marxistas, comunistas ou simpatizantes, como Georges Friedmann, André-Georges Haudricourt ${ }^{28}$, Charles Parain ${ }^{29}$ ou ainda André Varagnac ${ }^{30}$ - que, depois da Segunda

28 André-Georges Haudricourt (1911-1996), agrônomo de formação, foi aluno de Marcel Mauss. Próximo do Partido Comunista francês, desde os anos 1930, ele adotou uma abordagem de pesquisa marxista, atenta às técnicas. Publicou nos Annales seus primeiros trabalhos sobre o estudo das técnicas agrárias (especialmente, "De l'origine de l'attelage moderne", nos Annales HES, de novembro de 1936, p. 515-522, com uma introdução de M. Bloch) e foi um dos principais representantes da antropologia das técnicas no pós-guerra. Ver especialmente: Haudricour (1988).

29 Simpatizante comunista. Charles Parain (1893-1984) se especializa, ao longo dos anos 1930, no estudo das técnicas no meio rural, seguindo uma perspectiva marxista. Ele colabora ativamente com André Varagnac e André-Georges Haudricourt, principalmente no âmbito do Musée des Arts et Traditions Populaires. Ver sua coleção de artigos intitulados Outils, ethnies et développement historique, publicada nas Éditions Sociales em 1979.

30 André Varagnac (1894-1983) contribuiu fortemente, nos anos 1930, para a revalorização científica do folclore e tornou-se, ao lado de Georges-Henri Rivière, curador no Musée des Arts et Traditions Populaires. Ligado 
Guerra Mundial, desempenharam um papel central no desenvolvimento de estudos sobre o trabalho e as técnicas (GOUARNÉ, 2013). Além disso, essa temática reencontra um espaço proeminente entre os durkheimianos graças a Marcel Mauss, que adotou, no fim dos anos 1930, uma postura claramente "tecnófila" ao mostrar as técnicas como "características de cada estado social” (MAUSS, 2012).

Em reação ao discurso decadentista, que condenava a civilização moderna, havia surgido nas ciências sociais francesas um programa de estudos centrado nas técnicas e no trabalho. Apresentado por vezes como a origem da história das técnicas na França, esse programa foi pensado, nos anos 1930, não como um domínio de pesquisa específico, mas sob a forma de uma nova ciência social, definida em referência ao pensamento de Marx e centrada nas interaçóes entre o homem e seu meio. Ele correspondia, no entreguerras, a uma das principais tentativas de renovaçáo das ciências sociais durkheimianas - redefinindo seu projeto intelectual ao fazer do trabalho e das técnicas a matriz dos fatos sociais e sua ambição política ao interrogar de uma forma inovadora a questáo social e a crise política.

\section{A crise política como problema de "psicologia coletiva"}

A Jornada de estudos organizada por Ignace Meyerson em junho de 1941 foi a ocasião de reunir, uma vez mais, esse círculo intelectual fortemente mobilizado pela "defesa do progresso", no momento em que a retórica letrada antimoderna encontrou, com a Revolução Nacional, uma oportunidade política. Desde 1940, como destacou Francine MuelDreyfus (2004), os discursos de Pétain inscreviam a derrota no "esquema constrição/redenção", pois foi apresentada como "[...] uma punição infligida à França, que havia se prostituído face ao modernismo.” (PAXTON, 1997, p. 321). O colóquio de junho de 1941 pretendeu estudar e desconstruir justamente esse discurso ideológico ao torná-lo um problema de "psicologia coletiva" - a análise situada no plano das mentalidades, das representaçóes e das sensibilidades. O sucesso dos movimentos reacionários

ao movimento comunista, desde os anos 1920, ele reivindicou uma abordagem marxista em suas pesquisas sobre as culturas populares. Ele foi, contudo, entre 1941 e 1943, diretor do Bureau du Régionalisme em Toulouse, afastando-se dos meios intelectuais marxistas e de esquerda no pós-guerra. Sobre esse assunto. ver: Chandivert (2015). 
ou fascistas, para esses intelectuais, não poderia ser explicado pelo exame de suas doutrinas políticas. Ao contrário, era preciso esclarecer os fenômenos da "vida mental" que davam lugar a essas correntes políticas e às visóes retrógadas que veiculavam na sociedade. Seguindo essa abordagem, o programa da Jornada de 1941 estava estruturado segundo duas linhas de reflexão.

A primeira visava reinscrever as representaçóes e as ideias sobre o trabalho em uma perspectiva histórica. O simpósio da manhá, que deveria ser introduzido por Lucien Febvre, foi dedicado a esse tema. No texto de Lucien Febvre, enviado apenas depois da Jornada, mas publicado nos anais do colóquio, ele retraçava a evolução do sentido da palavra "trabalho" desde o século XVI. Dessa forma, atualizava o "ciclo" que havia conduzido da ideia do "trabalho como tortura" àquela do "trabalho na alegria", e realçava o movimento de revalorização social que o trabalho havia conhecido nas últimas décadas:

Não é de se admirar que finalmente as classes trabalhadoras tenham conquistado o direito à História porque eram trabalhadoras e não porque eram miseráveis. Uma dignidade chegou até eles e eles se tornaram objeto de inveja [...]. Antigamente, o epíteto do artesão, o epíteto do trabalhador era "vil". [...] Mas, três séculos depois, é a quem se concede o título de trabalhadores.

Assim, uma reflexão sobre o "valor moral" do trabalho foi elaborada no esforço de analisar a característica da mentalidade coletiva em conexão com os fatos da estrutura social. Várias perspectivas históricas foram propostas sobre a degradação social que o trabalho e as classes trabalhadoras conheceram na Antiguidade grega, nas épocas arcaicas e clássicas (André Aymard) ou sobre a visão cristã do trabalho (Paul Vignaux, o padre Étienne Delaruelle). Essa reflexão pretendia implicitamente dar uma resposta ao discurso de Vichy que, com a palavra de ordem "trabalho, família, pátria”, denunciava o "espírito do prazer" e via o trabalho como fonte da redenção.

A segunda temática abordada nessa Jornada, no âmbito do simpósio da tarde, introduzida por Marcel Mauss, faz referência à questão das relaçôes entre "técnicas e espírito". Na base dessa reflexão havia uma descoberta que Marcel Mauss resumia assim: 
Mesmo a ciência se torna cada vez mais técnica e a técnica age cada vez mais sobre ela. As pesquisas mais puras levam a resultados imediatos. [...] O círculo das relações ciênciatécnica é cada vez mais vasto, mas ao mesmo tempo mais fechado. É preciso apenas controlar o demônio descontrolado.

Assim, os efeitos dessa imbricação crescente entre ciência e técnica foram colocados em questão, o modo como modificava as "tendências originais da inteligência” (André Lalande) e, igualmente, as relaçóes entre diferentes grupos sociais. $\mathrm{O}$ mundo camponês foi objeto de particular atenção em razão da força de penetração dos movimentos fascistas nesse meio no contexto da crise agrária dos anos 1930, bem como do papel central que lhe foi atribuído na "restauração" da França pelo regime de Pétain. Em reação a esse discurso que pregava o retorno ao "real", à "terra que não mente", às comunidades "naturais" e aos equilíbrios milenares, Daniel Faucher e Marc Bloch se questionavam sobre o que chamamos comumente de "a rotina camponesa", ou seja, "a resistência dos trabalhadores da terra às novidades que lhes são ofertadas". Contra toda explicação naturalizante do social, que apelava para a "alma" camponesa, Marc Bloch afirmava que "[...] se a rotina camponesa incontestavelmente existe, ela não tem nada de absoluto.", uma vez que as sociedades camponesas poderiam se revelar por vezes muito inovadoras. Nessas condiçóes sociais, convinha pesquisar as causas desse "traço particular da mentalidade coletiva". A questão era, também nesse caso, tanto intelectual quanto política: de um lado, contestar o mito de um campesinato imóvel, eterno e homogêneo, ou seja, combater a concepção da ruralidade defendida por certos folcloristas e escritores, retomada nesse momento por Vichy ${ }^{31}$; de outro lado, compreender como adaptar as formas tradicionais de trabalho e de vida coletiva no meio rural à civilização moderna sem degradá-las ou desvalorizá-las.

Da mesma forma, a articulação entre mentalidade trabalhadora e progresso técnico foi examinada, a fim de criticar o esquema de percepção que estruturava a retórica antimoderna, qual seja a denúncia da "monotonia" e do "trabalho sem alegria" do trabalhador na civilização industrial. Não estava em questão, nessa Jornada de estudos, negar os efeitos nefastos do trabalho na linha de montagem, nem renovar uma exaltação ingênua da

31 Sobre esse debate do entreguerras, ver: Laferté (2009). 
modernidade científica e técnica. Georges Friedmann afirmava, na introdução de sua comunicação sobre a "psicologia do trabalho na linha de montagem"32: "no que diz respeito à mão de obra, não se duvida que a introdução maciça do trabalho na linha de montagem foi acompanhada de uma degradação maciça do trabalho qualificado" ${ }^{33}$. Contudo, sua análise estava voltada a uma reflexão sobre as condições da "humanização" do trabalho, sobre os esforços necessários para "reintegrar a personalidade do operário no trabalho na linha de montagem" e para "reencontrar indiretamente esses elementos de alegria no trabalho que caracterizam frequentemente o trabalho artesanal”.

\section{Journée d'Histoire et de Psychologie du Travail et des Techniques}

\section{3 de junho 1941}

Programa

Ignace Meyerson - O trabalho: uma conduta

I - História da ideia de trabalho

Lucien Febvre - Trabalho: evolução de uma palavra e de uma ideia

André Aymard - A ideia de trabalho na Grécia arcaica

Etienne Delaruelle - O trabalho nas regras monásticas ocidentais do quarto ao nono século

Paul Vignaux - Trabalho e teologia. Notas à margem de Proudhon

II - Técnicas e espírito

Marcel Mauss - As técnicas e a tecnologia

André Lalande - Técnica e ciência

Daniel Faucher - Rotina e inovação na vida camponesa

Marc Bloch - As transformações das técnicas como problema de psicologia coletiva

Charles Camichel - As características das técnicas modernas e seus efeitos

Georges Friedmann - Esboço de uma psicossociologia do trabalho na linha de montagem

32 Segundo Gwenaëlle Rot e François Vatin, essa exposição pode ser considerada "o ato fundador da sociologia do trabalho francesa" (ROT; VATIN, 2004).

33 Sobre a posição de G. Friedmann vis-à-vis da crítica do progresso, ver: Vatin (2004). G. Friedmann já havia dedicado duas obras à questão do maquinismo: Problèmes du machinisme en URSS et dans les pays capitalistes (FRIEDMANN, 1934); La crise du progrès. Esquisse d'histoire des idées, I895-I935 (FRIEDMANN, 1936). 


\section{Repensar o progresso: debate sobre o papel do intelectual}

Os diferentes ângulos adotados na Jornada de junho de 1941 convergem para uma mesma questáo: como repensar o futuro em um mundo que se tornou fundamentalmente instável e incerto? Como repensar a articulação entre o progresso social e a modernidade científica e técnica?

\section{As mentalidades coletivas face à modernidade}

Com efeito, essa preocupação com o futuro alarmou, durante o entreguerras, essas gerações de intelectuais, confrontados com o que podemos chamar, segundo François Hartog, uma "crise dos tempos". Em 1938, Lucien Febvre escreveu:

Este é um mundo que colapsa, desliza no abismo - e sob suas ruínas, novas forças já se organizam e surgem. [...] O mal-estar que nasce para todos nós das técnicas, a crise das técnicas, para ser breve, é irmã da grande crise econômica. Ela tem o mesmo significado e o mesmo futuro. É um mundo que se esvai. Podemos chorá-lo. Ele merece. Com tantos defeitos, ele tinha seus esplendores. Ele nos deixa belas obras para amar e a alegria que foi acumulada pelas gerações. Ele nos deixa vidas heroicas a apreciar e respeitar. Exemplos a seguir, se pudermos. Em primeiro lugar, a própria gênese - de sua emergência brutal, de seu nascimento súbito nas ruínas de uma grande civilização, de um grande Império, de um grande destino. [...] O mesmo significado, o mesmo futuro: qual futuro? Aqui, o historiador se recusa. Ele prevê apenas o passado. E segue o curso dos fatos. Porque a história é um teatro cuja cortina nunca deve cair. (FEBVRE, 1938a, p. 513-514).

Da mesma forma, Georges Friedmann, que em 1936 havia publicado, pela Gallimard, La Crise du Progrès - obra na qual tentou analisar as condiçóes dessa "retração do racionalismo" e das ideologias do progresso, declarava:

Muitos dos que me ouvem, talvez todos, diante da imagem de um campo e de um homem sozinho, com seus afazeres e seu cavalo, com as forças da terra e das estações, sentiram apenas uma simpatia imediata, não desprovida de grandeza, mas destinada a perecer sob o triunfo planetário da tecnologia. Não iremos chorá-la aqui. Pois essa simpatia levou, muitas vezes, ao seu oposto, à escravidão dos homens. Outras formas de simpatia vão amadurecer. Outros instintos, outras alegrias. [...] Esse período em que vivemos, entre dois mundos, é necessário e admirável por suas promessas. Mas, a partir de agora, o homem deve, urgentemente e em todo lugar, segurar as rédeas do seu destino em suas mãos. (FRIEDMANN, 1945). 
Essas gerações intelectuais, marcadas pelas lutas antifascistas dos anos 1930-1940, pensavam estar situadas em uma "lacuna" (HARTOG, 2003) entre a impossibilidade do passado, já que a sociedade antiga estava em vias de desaparição sob o efeito da modernização técnica, e a impossibilidade do futuro, já que a sociedade futura não havia ainda sido inventada. De certa maneira, essas geraçóes questionavam, a partir de uma história das mentalidades coletivas, o "descompasso" entre os fatos e o pensamento: o problema era, para esses intelectuais, compreender os "limites do pensável" e as causas do "bloqueio" entre os fenômenos da mentalidade coletiva e o desenvolvimento técnico para, assim, superá-los. Como escreveu Marc Bloch em L'Étrange Défaite, tratava-se de:

Formar uma ideia clara das necessidades sociais e se esforçar para disseminá-la [a fim de] introduzir um novo grão de fermento na mentalidade comum; [e] dar-se uma chance de modificá-la um pouco e, portanto, de alterar em alguma medida o curso dos acontecimentos que são regulados em última instância pela psicologia dos homens. (BLOCH, 1990, p. 205).

Essa questão de pesquisa foi posta em evidência nessa Jornada de junho de 1941 por estar relacionada às preocupaçôes imediatas desses intelectuais. Estes viam na crise política que o país atravessava o resultado da incapacidade da sociedade, especialmente das elites, de antecipar o futuro - e daí o sucesso, com Vichy, das soluçóes retrógadas, que consistiam em buscar no passado a solução para os problemas do presente. Os intelectuais reunidos naquela Jornada de estudos se colocavam em contraposiçáo a tais soluçôes - seja pelos seus engajamentos na Resistência; seja por suas reflexôes sobre o progresso e a modernidade.

\section{O “problema da representação concreta do futuro” (Canguilhem)}

Assim, não é por acaso que, em 1948, ao escrever uma resenha das atas da Jornada de junho de 1941, Georges Canguilhem se depare com esse "problema da representação concreta do futuro" 34 . Engajado no movimento antifascista nos anos de 1930 - depois de ter rompido com o pacifismo integral defendido por seu "mestre", o filósofo Alain (Émile Chartier) -,

34 Resenha publicada em Canguilhem, 1940-1948. 
Canguilhem estava engajado na Resistência desde 1941, além de ter assistido à Jornada de estudos organizada por Ignace Meyerson. Sua resenha sobre a Jornada, que foi publicada juntamente com as atas, em 1948, destacou o "valor científico" das comunicaçôes e seu alcance político diante "das elucubraçóes sem interesse dos pensadores de Vichy” - ainda que criticasse os pontos de vista defendidos por Marcel Mauss e Marc Bloch:

O último problema abordado, ele observa, é a tomada de consciência da importância dos fatos técnicos. Trata-se de explicar por qual motivo a invenção técnica não é necessariamente acompanhada pelo esforço de imaginação prática, econômica e social, que permite compreender antes do evento seu desempenho e seu alcance possíveis. Minha admiração por Marc Bloch, seu talento, seu fim heroico não me impede de perguntar se este último problema não estaria mal colocado. [...] Está em questão todo o problema da representação concreta do futuro. Assim como na biologia, o problema das relações entre o órgão e a função também se coloca. Em que momentos o homem percebeu que ele possui novos órgãos? O órgão pode aparecer como tal apenas em relação a uma função. Não concordo com o Sr. Mauss quando escreve (p. 75) que "a ideia bergsoniana da criação é exatamente o oposto do tecnicismo". A tese bergsoniana, se bem desenvolvida, mostraria a tecnologia como um capítulo de uma organologia geral.

Assim, Canguilhem convidava a considerar a técnica não como uma aplicação das ciências, mas como "[...] um fenômeno biológico universal." (CANGUILHEM, 2009, p. 163), ou seja, como "[...] uma forma concreta e pré-reflexiva de solução dos problemas da vida." (CANGUILHEM, 1949, 2015). Segundo ele, era equivocado considerar as atitudes de rejeição dos operários e dos camponeses diante do emprego crescente da máquina como resultado de um "bloqueio" das mentalidades em relação ao desenvolvimento técnico - bloqueio que levaria, segundo a fórmula de Marc Bloch, a "um problema de psicologia coletiva", qual seja o "contato entre os grupos sociais" e a "interpenetração entre as diferentes classes". Para Canguilhem, as resistências dos trabalhadores ao maquinismo deviam, ao contrário, ser "[...] compreendidas como reaçóes da saúde: seja como defesa biológica, seja como defesa social.", a partir das quais poderia se inventar novas técnicas que levassem à resolução desses "problemas de adaptação" (CANGUILHEM, 1947a; 2015, p. 301).

Essa crítica do otimismo racionalista das ciências sociais francesas constituía uma tomada de posição original, mas pouco conhecida, no campo intelectual do pós-guerra - marcado por “[...] uma forte politização 
que se traduziu pela bipolarização entre esquerda e direita, pela hegemonia do Partido Comunista no polo radical do campo intelectual, pela ascensão do marxismo à posição de paradigma filosófico legítimo e pelo debate sobre o papel e a missão do intelectual.” (SAPIRO, 2007, p. 131). Apesar de seu engajamento na Resistência armada, Canguilhem foi uma figura discreta nos debates do pós-guerra sobre o papel dos intelectuais que opunham principalmente os defensores de uma filosofia do sujeito (Sartre, Merleau-Ponty) e os intelectuais comunistas. É apenas na efervescência política e intelectual dos anos 1960 que a postura crítica de Canguilhem encontrará um eco real, por meio, notadamente, das retomadas que foram feitas por toda uma geração de filósofos (Althusser e seus alunos, Foucault, Bourdieu e outros).

Entretanto, sua postura crítica se enraizava em sua experiência política e no momento antifascista dos anos 1930-1940, como destacará Michel Foucault em seu célebre artigo "La Vie: l'Expérience et la Science" (A vida: a Experiência e a Ciência). Nesse artigo, ao analisar a "linha de divisão que separa [na história do pensamento francês] uma filosofia da experiência, do sentido e do sujeito, e uma filosofia do saber, da racionalidade e do conceito", ele visava esclarecer esse paradoxo:

Aparentemente, a segunda permaneceu a um só tempo a mais teórica, a mais regulada por meio de tarefas especulativas, bem como a mais afastada das questões políticas imediatas. No entanto, foi ela que, durante a guerra, tomou parte de maneira muito direta no combate, como se a questão do fundamento da racionalidade não pudesse ser dissociada da interrogação sobre as condições atuais da existência. (FOUCAULT, 1985, p. 4).

Ao questionar o papel e o status do saber, a filosofia de Canguilhem voltava-se a "[...] desintelectualizar tanto quanto possível os fenômenos da ciência e do conhecimento." (MACHEREY, 2009, p. 118). Ela refutava assim o papel fundador atribuído ao conhecimento e recusava toda posição de projeção ao cientista, convidando a pensar as relaçóes do cientista e do popular fora de toda forma de cientificismo. "A célebre fórmula 'saber para predizer a fim de poder' é tão enganadora quanto famosa.”, já havia notado Canguilhem em 1938 (CANGUILHEM, 2011, p. 504). Tal concepção levava, segundo ele, a uma visão mecanicista do homem, pois permanecia presa à ilusão científica que pretendia solucionar os problemas sociais a 
partir das ciências e de um conhecimento mais fino das transformaçôes da sociedade e se mostrava de fato incapaz de "[...] remeter o mecanismo ao seu lugar na vida e para a vida”. Como ele notou em 1947: esse problema é talvez aquilo que está em questão "[...] sob os aspectos trágicos dos conflitos do passado recente e também - é preciso dizê-lo - do futuro próximo?” (CANGUILHEM, 1947b; 2015, p. 320).

No pós-guerra, essa crítica visava particularmente à orientação seguida pelo marxismo, elaborado na filosofia e nas ciências sociais francesas, desde os anos 1930, como refúgio do racionalismo (GOUARNÉ, 2013). Embora no momento do Front Populaire, Canguilhem havia se reaproximado dos círculos marxistas comunistas e saudado as renovaçóes que eles introduziam ${ }^{35}$, o marxismo francês estava, a seus olhos, fechado em uma visão mecanicista:

A recuperação da alienação é total apenas na medida em que o homem recupera, não somente sua dignidade política, mas também sua plenitude vital de um ser que domina o mecanismo universal - cuja forma maquinista da técnica é apenas um aspecto - em vez de ser dominado por ele. Isso significa que, se houver dialética, é necessário que a inversão do mecanismo-organismo também seja operada. [...] Nós não vemos os racionalistas dialéticos na França se preparando para efetuar essa inversão, pois apesar de suas afirmações de ruptura e de renovação, eles ainda se deixam levar pela ilusão cientificista, forma secularizada e endurecida do racionalismo clássico, isto é, um estilo de vida ligado ao crescimento econômico da classe capitalista, classe cujos princípios de autojustificação consistem em considerar a totalidade da experiência, dos vivos e homens incluídos, como objetos cujo uso técnico pressupõe sua redução prévia a um mecanismo. (CANGUILHEM, 1947b, p. 318-319).

A exemplo do campo literário sob Ocupação alemã, estudado por Gisèle Sapiro, as acusaçóes que visavam os meios científicos republicanos contribuiráo para "[...] reunir aqueles que tentavam resistir à importação de lógicas heterônomas em uma luta pela reconquista da

35 Em 1935, enquanto o marxismo suscitava um vivo interesse intelectual, em primeiro lugar entre os círculos comunistas, Georges Canguilhem abria nas Feuilles Libres de la Quinzaine uma "crônica marxista", que ele concebeu como "[...] um exercicio de método marxista, tal como se pensaria o dever de compreender, a propósito dos problemas e dos eventos precisos a resolver ou a interpretar". No final de 1935, por exemplo, ele listou o panfleto de René Maublanc, La Philosophie du Marxisme et l'Enseignement Officiel, notando que: "O marxismo é uma filosofia total, uma concepção do mundo, cuja importância reside mais em suas promessas do que em suas realizações". Ver: Canguilhem (20II, p. 480-484 especialmente). 
autonomia.” (SAPIRO, 1999). O colóquio organizado em junho de 1941 em Toulouse por Ignace Meyerson sobre "a história e a psicologia do trabalho e das técnicas" exemplifica essa mobilização coletiva das ciências sociais republicanas, ignorando clivagens intelectuais, disciplinares e políticas: diante das acusaçôes nostálgicas dos pensadores de Vichy, o objetivo era reafirmar a vocação racionalista das ciências sociais francesas e sua função crítica.

Os esforços empregados para sair dos esquemas de pensamento impostos, reformulando em uma problemática intelectual (por meio da reflexão sobre o trabalho e as técnicas) as questôes sociais e políticas do momento, revelam também indiretamente as incertezas nas quais foram postas as ciências sociais republicanas: toda uma reflexão sobre o papel dos saberes e de seus impactos sobre a sociedade foi desenvolvida nesse momento antifascista. Ao mesmo tem em que a entrada na luta política e armada contra Vichy e o ocupante levaram alguns a redefinir o sentido do trabalho intelectual, a pretensão das ciências de poder dar uma resposta racional aos problemas sociais e políticos foi colocada em dúvida.

Sem dúvidas, é preciso ler os escritos filosóficos de Georges Canguilhem à luz do debate sobre o papel do intelectual, como se depreende da leitura crítica que ele fez dos trabalhos da Jornada de estudos de junho de 1941: sua filosofia convidava de fato a considerar o significado da crise social e política não como uma derrota da Razão diante das derivas do irracionalismo, mas como "[...] uma ressurgência patológica da ideia do progresso." (MACHEREY, 2009, p. 123), para a qual somente a ação e "a experiência dos vivos" podem apontar soluçôes, apelando para uma nova conceitualização do conhecimento e da racionalidade. Questionandose, em um de seus últimos escritos, sobre "[...] as condiçôes nas quais a ideia de progresso perdeu seu prestígio e seu papel.”, Georges Canguilhem apontou assim os impasses a que chegou o pensamento racionalista - incluindo a formulação marxista, que, mantendo a ideia do progresso na "sua função cultural de antecipação milenarista", havia sido tomada pelas contradiçôes desse século - século esse, concluiu citando Freud, em que "[...] nós descobrimos com surpresa que o progresso fez um pacto com a barbárie.” (CANGUILHEM, 1987). 


\section{Referências}

ALMARIC, J. P. Terribles et grandioses: les années toulousaines de Georges Friedmann, 19401945. In: GREMION, P.; PIOTET, F. (Dir.). Georges Friedmann, un sociologue dans le siècle, 1902-1977. Paris: CNRS Éditions, 2004. p. 29-49.

BIARD, A.; BOUREL, D.; BRIAN, É. (Ed.). Henri Berr et la culture du XXe siècle. Paris: A. Michel, 1997.

BLOCH, M. A Estranha derrota. Testemunho escrito em 1940. Rio de Janeiro: Zahar, 2011. L'Étrange défaite. Témoignage écrit en 1940. Paris: Gallimard, 1990.

Carta de Marc Bloch a Ignace Meyerson, de 22 de maio de 1941. Fonds I. Meyerson, Archives nationales, 521AP/47, 1941.

BOUlLAND, P.; PENNETIER, C. (Dir.). Le Maitron en ligne. Dictionnaire biographique. Mouvement ouvier/Mouvement social. Paris: Éditions de l'Atelier, 2012.

CABANEL, P. Pétainisme et résistance intellectuelle: l'Institut catholique de Toulouse dans les années 1940. In: GUESLIN, A. (Dir.). Les Facs sous Vichy. Étudiants, Universitaires et Universités de France pendant la Seconde Guerre Mondiale. Clermont-Ferrand: Institut d'études du Massif Central/Université Blaise Pascal, 1994. p. 263-284.

CANGUILHEM, G. Résistance, philosophie biologique et histoire des sciences 1940-1965. Paris: Vrin, 2015. Écrits philosophiques et politiques 1926-1939. Paris: Vrin, 2011. p. 499-506.

. Machine et organisme. In: La connaissance de la vie. Paris: Vrin, 2009 [1965]. p. 129-164.

La décadence de l'idée de Progrès. Revue de métaphysique et de morale, Paris, p. 437454, out./dez. 1987.

Progrès technique et progrès mora. L’Année sociologique, Paris, (s.n), p. 785-791, 1949.

Relatório da coleção Progrès technique et progrès moral (Rencontres internationales de Genève, 1947). Neuchâtel: Éditions de la Baconnière, 1948.

Milieu et Normes de l'Homme au Travail (À propos d'un live récent de Georges Friedmann). Cahiers internationaux de sociologie, Paris, v. 3, 1947a. Disponível em: <http:// temporalites.free.fr/?browse=Milieu $\% 20$ et $\% 20$ Normes $\% 20 \mathrm{de} \% 201 \% 27$ homme $\% 20 \mathrm{au} \% 20$ travail>. Acesso em: abr. 2018. 
Note sur la situation faite en France à la philosophie biologique. Revue de métaphysique et de morale, Paris, v. 52, n. 3./4, p. 322-332, jul./out. 1947b.

l'Année sociologique Technologie. Traits généraux, (S.l.), t. 2, p. 773-775, 1940-1948. ( $3^{\mathrm{e}}$ série).

Activité technique et création. Communications et discussions, Toulouse: Société toulousaine de philosophie, Faculté des Lettres, 1937-1938. (2ª série).

CARROY, J.; OHAYON, A.; PLAS, R. Histoire de la psychologie en France, $\mathbf{X I X}^{\mathrm{e}}$ et $\mathbf{X X}^{\mathrm{e}}$ siècles. Paris: La Découverte, 2006. p. 141-148.

CHANDIVERT, A. Sciences sociales, Résistance et 'mystique provinciale' à Toulouse sous le gouvernement de Vichy. Complexité et ambivalence des engagements, 1930-1950. Revue d'histoire des sciences humaines, (S.1.), v. 28, p. 191-223, 2016.

André Varagnac et les contraintes de l'histoire. La trajectoire tourmentée d'un folkloriste après-guerre. Ethnologie française, Paris, v. 45, n. 1, p. 167-174, 2015.

CHARLE, C. La République des universitaires, 1870-1940. Paris: Seuil, 1994.

Naissance des intellectuels. Paris: Éditions de Minuit, 1990.

DROUARD, A. Une inconnue des sciences sociales. La Fondation Alexis Carrel 1941-1945. Paris: Éditions MSH, 1992.

FABIANI, J. L. Qu'est-ce qu'un philosophe français. Paris: Éditions EHESS, 2010.

. À quoi sert la notion de discipline? In: BOUTIER, J.; PASSERON, J. C.; REVEL, J. (Dir.). Qu'est-ce qu'une discipline? Paris: Éditions de l'EHESS, 2005. p. 7-30.

FEBVRE, L. Les techniques, la science et l'évolution humaine. Europe, p. 498-514, out. 1938a. L'histoire en France dans les dix dernières années. Science, v. 3, p. 95, maio 1938b. [Texto reeditado por MULLER, B. em Genèses, v. 34, p. 132-143, mar. 1999].

FOUCAULT, M. A vida: a experiência e a ciência. In: MOTA, M. B. Arqueologia das ciências e história dos sistemas de pensamento. Rio de Janiro, Forense universitária, 2005. p. 352-366. (Ditos e Escritos, II).

La vie: l'expérience et la science. Revue de métaphysique et de morale, Paris, v. 90, n. 1, p. 3-14, jan./mar. 1985.

FRIEDMANN, G. La crise du progrès. Esquisse d'histoire des idées. 1895-1935. Paris: Gallimard, 1936. 
Machine et humanisme. Europe, p. 437-444, jul. 1935. [Teses apresentadas no Congrès international des Écrivains pour la Défense de la Culture, Paris, jul. 1935].

Problèmes du machinisme en URSS et dans les pays capitalistes. Paris: Éditions sociales internationales, 1934.

GEIGER, R. La sociologie dans les écoles normales primaires: histoire d'une controverse. Revue française de sociologie, Paris, v. 20, n. 1, p. 257-267, 1979.

GOBILLE, B. Lévénement Mai 68. Pour une sociohistoire du temps court. Annales HSS, Paris, v. 2, p. 321-349, mar./abr. 2008.

GOUARNE, I. L'introduction du marxisme en France. Philosoviétisme et sciences humaines 1920-1939. Rennes: PUR, 2013.

GOUARNE, I. La Conférence de psychotechnique, VII ${ }^{e}$., Moscou, septembre 1931. Cahiers d'histoire. Revue d'histoire critique, n. 102, p. 65-87, 2007.

GREMION, P.; PIOTET, F. (Dir.). Georges Friedmann: un sociologue dans le siècle, 1902-1977. Paris: CNRS Éditions, 2004. p. 81-89.

HARTOG, F. Régimes d'historicité. Présentéisme et expériences du temps. Paris: Seuil, 2003.

HAUDRICOURT, A. G. Technologie, science humaine. Paris: Éditions MSH, 1988.

HEILBRON, J. French Sociology. Ithaca; Londres: Cornell University Press, 2015.

HENRY, O. Les Guérisseurs de l'économie. Ingénieurs-conseils en quête de pouvoir. Paris: CNRS Éditions, 2012.

JANKELEVITCH, V. L’esprit de résistance. Textes inédits, 1943-1983. Textes réunis et présentés par F. Schwab avec les contributions de J.-M. Brohm et J.-F. Rey. Paris: A. Michel, 2015.

JARRIGE, F. Techno-critiques. Du refus des machines à la contestation des technosciences. Paris: La Découverte, 2014.

LAFERTE, G. L'appropriation différenciée des études folkloriques par les sociétés savantes: la science républicaine rétive au folklore. Revue d'Histoire des Sciences Humaines, Paris, n. 20, p. 129-162, 2009.

LAHIRE, B. Pour une sociologie. Et pour en finir avec la culture de l'excuse. Paris: La Découverte, 2016.

LÓPEZ, N. P. La psychologie historique d'Ignace Meyerson. 2008. Tese (Doutorado em Psicologia) - Université Paris Descartes. Université Complutense de Madrid, Paris/Madri, 2008. 
MACHEREY, P. De Canguilhem à Foucault, la force des normes. Paris: La Fabrique éditions, 2009.

MARCEL, J.C. Mauss et Halbwachs: vers la fondation d'une psychologie collective (1920-1945)?

Sociologie et sociétés, Montreal, v. XXXVI, n. 2, p. 73-90, 2004.

MAUSS, M. Techniques, technologie et civilisation. Édition et présentation de Nathan Schlanger. Paris: PUF, 2012.

. Une catégorie de l'esprit humain: la notion de personne. Celle de 'moi'. In:

Sociologie et anthropologie. Paris: PUF, 1990 [1950]. p. 331-362.

MEYERSON, I. Prefácio da Jornada de Estudos. Journal de psychologie normale et pathologique, 1948. [Número especial "Le travail et les techniques"].

MUCCHIELLI, L. La découverte du social. Naissance de la sociologie en France. Paris: La Découverte, 1998.

Sociologie et psychologie en France, l'appel à un territoire commun: vers une psychologie collective, 1890-1940. Revue de synthèse, Paris, n. 3./4, p. 445-476, jul./dez. 1994.

MUEL-DREYFUS, F. La rééducation de la sociologie sous le régime de Vichy. In: HEILBRON, J. et al. Pour une histoire des sciences sociales. Paris: Fayard, 2004. p. 107-124.

MUEL-DREYFUS, F. Vichy et l'éternel féminin. Paris: Seuil, 1996.

PAROT, F.; RICHELLE, M. (Dir.). Psychologues de langue française. Paris: PUF, 1992. p. 4-30.

PAXTON, R. O. La France de Vichy. Paris: Seuil, 1997 [1972].

PROCHASSON, C. Les intellectuels, le socialisme et la guerre. Paris: Seuil, 1993.

RACINE, N. Benjamin Crémieux et le Pen Club. In: COMPAGNON, A. (Dir.). La République des Lettres dans la Tourmente, 1919-1939. Paris: CNRS/Alain Baudry et Cie, 2011. p. 133-149. RAIMOND, M. Éloge et critique de la modernité. Paris: PUF, 2000.

RASMUSSEN, A. Critique du progrès, crise de la science: débats et représentations du tournant du siècle. Mil neuf cent, Paris, v. 14, p. 89-113, 1996.

ROSENTAL, P. A. L'intelligence démographique. Sciences et politiques des populations en France, 1930-1960. Paris: O. Jacob, 2003. p. 69-72.

ROT, G.; VATIN, F. Les avatars du 'travail à la chaîne' dans l'œuvre de Georges Friedmann, 19311966. Genèses, v. 57, p. 23-40, dez. 2004. 
ROUQUET, F. «Mon cher Collègue et Ami». L'épuration des universitaires, 1940-1953. Rennes: PUR, 2010.

SAPIRO, G. Pierre Naville et Jean-Paul Sartre: une controverse sur le rôle social de l'intellectuel. In: BLUM, F. (Dir.). Les vies de Pierre Naville. Lille: Presses universitaires du Septentrion, 2007. p. $127-141$.

SAPIRO, G. Le savant et le littéraire. Les hommes de lettres contre la sociologie durkheimienne. In: HEILBRON, J. et al. (Dir.). Pour une histoire des sciences sociales, Paris: Fayard, 2004. p. $83-106$.

SAPIRO, G. La guerre des écrivains, 1940-1953. Paris: Fayard, 1999. p. 106-160.

SERRY, H. Saint Thomas sociologue ? Les enjeux cléricaux d'une sociologie catholique dans les années 1880-1920. In: HEILBRON, J. et al. (Dir.). Pour une histoire des sciences sociales. Paris: Fayard, 2004. p. 59-81.

SINGER, C. Vichy, l'Université et les juifs. Les silences et la mémoire. Paris: Les Belles Lettres, 1992.

TURBIAUX, M. J.-M. Lahy. 1872-1943. et l'orientation professionnelle. Bulletin de psychologie, t. 59, n. 2, p. 217-235, mar./abr. 2006.

TURBIAUX, M. J. M. Lahy. 1872-1943: essai de bio-bibliographie. Bulletin de psychologie, t. XXXVI, n. 362, p. 969-985; 1982-1983.

VATIN, F. L'espérance-monde. Essai sur l'idée de progrès à l'heure de la mondialisation. Paris: A. Michel, 2012.

VATIN, F. Machinisme, marxisme, humanisme: Georges Friedmann avant et après-guerre. Sociologie du travail, Paris, n. 46, p. 205-223, avril/juin 2004. 


\section{Crisis of Progress, Antifascism and Social Sciences: the Journée d'histoire et de psychologie du travail et des techniques (Toulouse, june 194I)}

\section{Abstract}

In June 1941 a colloquium on "the psychology and the history of technics and labour" was organized in Toulouse with the participation of several important social sciences researchers of the interwar period (Marc Bloch, Lucien Febvre, Marcel Mauss, Georges Friedmann, Ignace Meyerson and others). This scientific encounter was one of the rare moments of collective reflection that could be held during World War II in the French social sciences in spite of the violent political charges brought against them by Vichy regime. This 1941 colloquium attests the efforts made in order to reaffirm the social and political role of the social sciences of the Durkheimian tradition: in a context of strong politicisation, their intellectual project, because it had to be defended, was clarified and expanded in its different aspects: the scientific mode of organisation it involved, the particular perspective it adopted on the social and political crisis and also the affinities it had with the ideology of progress.

Keywords: Social sciences. Political crisis. Commitment. Word War II.

Recebido em: 17.08.2017

Aprovado em: 30.01.2018 